\title{
The Ecosystem Approach in military operations: no security without ecological security, no stability without sustainability
}

\author{
Kim Janssen ${ }^{1 *}$ and Piet Wit ${ }^{2}$
}

\begin{abstract}
Janssen, K., Wit, P. 2011. The Ecosystem Approach in military operations: no security without ecological security, no stability without sustainability. - Forestry Studies | Metsanduslikud Uurimused 54, 48-53. ISSN 1406-9954.

Abstract. This paper describes a recently developed training module on the "ecosystem approach", with the military as target group. Initiated by NATO-affiliated Civil-Military Co-operation Centre of Excellence (CIMIC COE), the module fits into a multidisciplinary new training approach, in which the military learns to integrate specific concepts into their missions, such as environmental issues. In developing the training module, a combination of the Rapid Ecological Assessment (REA) and Rapid Rural Appraisal (RRA) techniques has been formed into a stepwise approach for military to enable them to quickly scan and analyse important environmental issues in their mission environments. The result of the training module is an instructive publication and an attached instruction card, the latter being a tool commonly used by military.
\end{abstract}

Key words: rapid rural appraisal, rapid ecological assessment, ecosystem approach, military.

Authors' address: ${ }^{1}$ Euroconsult/BMB Mott MacDonald, Amsterdamseweg 15, Arnhem, The Netherlands, *e-mail: kim.janssen@mottmac.com

${ }^{2}$ Chair of the Commission on Ecosystem Management, IUCN Conservation Centre, Rue Mauverney 28, 1196, Gland, Switzerland, wit@syzygy.nl

\section{Introduction}

The establishment of a secure and stable environment in which an affected society can regain their confidence in a sustainable future is one of the main goals for a military operation during and after a man-made or natural catastrophe. During the early phases of the operation, access for the local communities to land, water, plants and animals may only be established with the assistance of the military forces. Under that military shelter people can regain confidence to invest their time and money in growing their own food, protecting their water resources, restoring their forests, managing their fish stocks and enjoying their landscape for cultural reasons. Proper ecosystem management therefore is essen- tial to reconstruct such key-sectors as agriculture and animal husbandry, water management, forestry and recreation. It brings security and stability to the population and - in the case of peace support operations - contributes substantially to the achievement of military goals.

Within the military environment, recognition has grown to the fact that, in order to achieve long-term societal improvement through military operations, integral knowledge and familiarity with concepts such as gender, governance, and ecological security are essential. The NATO-affiliated CIMIC Centre of Excellence (CCOE) a military training centre established in Enschede, The Netherlands, has developed training modules on each of these themes in support of the 3D approach, which stands 
for Defence, Diplomacy and Development in Military operations. This paper outlines the development of the training module that promotes the integration of ecological security as early as possible into military operations, as it is generally recognised that unlike infrastructural works, ecological losses may be irreversible on a human time scale, and should be avoided where possible.

\section{Material and Methods}

\section{The Ecosystem Approach}

The fifth Conference of the Parties to the Convention on Biological Diversity defines the Ecosystem Approach as 'a strategy for the integrated management of land, water and living resources that promotes conservation and sustainable use in an equitable way'. The corresponding 12 principles to the Ecosystem Approach (Appendix 1; Shepherd, 2008) served as principal guidance in developing the methodology for the training module, as they touch upon the most crucial aspects regarding human interventions and ecology, being: the availability of natural resources, the socio-economic use of those resources, the management of those resources and the integral interaction between all these aspects.

\section{Rapid Rural Appraisal (RRA) and Rapid Ecological Assessment (REA)}

The target group for this particular training module are in the first place military commanders in the field, such as the officers leading a platoon. The method developed for the training module covers the objectives of commonly used Rapid Rural Appraisal and Rapid Ecological Assessment methodologies. A combination of the two methods was chosen as to enable a balanced use of the Ecosystem Approach concept (see section The Ecosystem Approach) in producing a stepwise instruction for the target group.

Rapid Rural Appraisal (RRA) was developed through the 70s and elaborated in the 80s and 90s further into a Participatory Rural Appraisal (PRA) methodology as to put more focus on addressing participatory techniques. Chambers (1994) describes Rapid Rural Appraisal as a method that seeks to "enable outsiders to gain information and insight from local people and about local conditions, and to do this in a more cost-effective and timely manner". Over the years this technique has been applied mostly in farming environments by institutions such as the Consultative Group on International Agricultural Research Centers (CGIAR). Being characterized as actionoriented research, RRA commonly combines survey techniques, focus group interviewing techniques, site level observations, and cross-checking information methods, amongst others (Chambers, 1994).

Consequently, Rapid Ecological Assessment (REA) is a so-called biodiversity survey methodology primarily developed by The Nature Conservancy over the past two decades Sayre et al. 2000). REA has been developed to function as a tool to fill the gap of available information on the quantity and quality of natural resources. Sayre et al. (2000) define REA as a "flexible, accelerated, and targeted survey of vegetation types and species" that produce "baseline biophysical data, maps, documents, recommendations, and increased institutional capabilities for effective conservation work". In contrast with the Rapid Rural Appraisal methodology, Rapid Ecological Assessment thus puts the focus on the availability of natural resources themselves without explicitly considering (the impacts of) human activities in relation to those resources.

The methodology used for the training module is based on one of the author's earlier experiences with training of non-ecologists to integrate environmental considerations in their activities, such as Water Board Engineers in Indonesia, Road designers at the UNESCO-IHE Delft (Institute for Water Education) and Tour operators from Mongolia. The methodology as developed for the military as target group differs from 
those previous experiences in two important ways. Military usually are not educated primarily in ecology, and they may not be all that familiar with environmental issues. The training module therefore, more than in previous cases, puts attention to awareness raising and familiarizing the military with environmental concepts and issues.

Second of all, military on mission are often not in the position to conduct indepth surveys or long interviews with farmers and other locals, as this may affect their security. This means that, in the training module, it is explained that often conditions are such that situations may not be fully assessed. However, even a not fully completed assessment can gain valuable insights in environmental aspects in a situation to guide further action.

\section{Stepwise REA for the military}

In making the combined Rapid Rural Appraisal (RRA) and Rapid Ecological Assessment (REA) methodology understandable and workable for militaries on their missions, a cut-and-clear and readyto-apply technique was developed (hereafter referred to as REAMil assessment). In creating a realistic picture and applicable technique, sources of importance were:

- Case studies about environmental impacts of conflict and natural disasters, and about relief operations in response to such events, drawn from practical past experience, by military personnel and relief organisations;

- Relevant (military-related) literature;

- Background material for International Conventions.

In creating the training module in a way that easily familiarizes the target group with the learning method, current study material as used by military in training was revised and taken as model. So-called "ICs" (Instruction Cards) are commonly used as a backbone in the field to remind the military of stepwise actions to be taken in relevant situations. In addition to the training mod- ule on REAMil, an instructive publication and an instruction card were developed providing a schematic overview of the most important components that comprise each of the steps in a REAMil assessment.

It is important to realise that unlike researchers doing RRA and REA for instance in the context of a Rural Development Programme, military personnel have only a limited knowledge of ecological issues, including the application of this in sectors like agriculture or fisheries, and that for security reasons they have no time to spend days with villagers in the field to discuss their resource use, their local economy etc.

\section{Results}

The outcome has provided for a combined publication and training module, with checklist tables complementing the stepwise REAMil assessment. Background information supports the checklists, with explanations illustrated by many practical examples and case studies as to enable a quick and easy learning environment for the target group.

Starting from theory, the three dimensions of the Ecosystem Approach (see Figure 1), developed by one of the authors, provide the building blocks for a four-step military specified REA instruction. These principles make clear distinctions between three interrelated dimensions, being (i) the

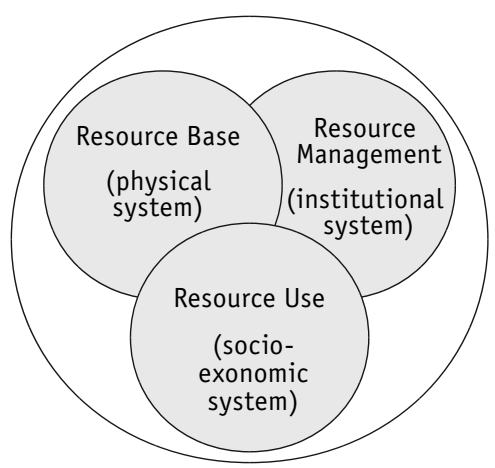

Figure 1. The three dimensions of the Ecosystem Approach 
natural system or the resource base, (ii) the socio-economic system which deals with the use of the resource base and (iii) the institutional system that addresses the management of the resource base and its different uses. As is visualized in Figure 1, these three dimensions are interconnected: dynamics in one dimension create conditions for the other dimensions and vice versa.

The three dimensions as described form the first three steps in the REAMil assessment developed for the training module. Step 1 therefore covers the assessment of the resource base, where important aspects of the physical system are analysed, such as available clean water in an area and occurring vegetation types. Entry points for this step are the abiotic and biotic ecosystem components, organised according to the food chain paradigm. Step 2 then covers the assessment of resource use, how local people in an area make specific use of available resources (water for drinking and washing, agriculture). Entry point here are the (major) stakeholders of an area and the use they make of the components described under step 1. Step 3 consequently covers assessing the resource management, modern and traditional management institutions including the law and regulatory system around resource use in an area. In addition, the publication adds Step 4 to the assessment, in which the three previous steps are analysed together as to evaluate potential impacts of military operations on the environment and to identify opportunities for reconstruction activities. This with keeping the objective in mind to effectively take actions to enhance environmental security and to support local livelihoods for sustainable recovery and development.

The corresponding (draft) instruction card, developed to give a one-page schematic overview of all steps in order to allow quick assessment, is shown in Appendix 2. It covers the components that require attention in each step, as well as it shows through arrows in which way (groups of) components relate to one another.

\section{Discussion}

\section{REAMil validity in military environments}

The Rapid Ecological Assessment tool for the military has specifically been designed to be applied in fragile states where the military has a presence. Though, depending on conditions within particular fragile environments, several issues might arise that cause an incomplete outcome of the assessment. It is quite likely that, especially in circumstances of escalated (political) instability, important resource persons are inaccessible or are not in the position to give uncensored information, creating an obstacle to making a complete and realistic situational analysis. In addition, the dynamic characteristics of the political spheres and interventions in fragile states might put issues to the actuality of Step 3 outcomes. These are issues that cannot always simply be overcome, though they do stress to continuously be critical to the analysis of the steps in REAMil. Continuous reviewing, reassessing, and updating the steps of REAMil is absolutely a prerequisite to plan realistic and effective Step 4 interventions, and as such, create REAMil outputs that show to be valid for use in military environments.

\section{Ecological security: who's responsible?}

In providing military with instructions to conduct an assessment as proposed in the training module, and to use the tool in making mission-related decisions, questions around who is responsible for what arise. Specifically, to what end is the military responsible for ensuring ecological security in the environments where they operate? To what extent is it the responsibility of respective governmental bodies, actively operating NGOs, or other present organisations and institutions?

The created training module emphasises the fact that ecological security is a matter of combined efforts of all stakeholders involved, with governmental agencies and civil society organisations who are 
designated to environmental management at the core.

Relating to this, the training module builds upon the principle of subsidiary. Even though taking environmental aspects into account in reconstruction and other mission-related work is of essential importance to achieve the objectives of the military operations, environmentally focussed activities themselves should be handed over to the appropriate governmental agencies and civil society organisations as soon as the general security situation permits it.

\section{Conclusions}

The described training module and publication are based on experiences of the authors in guiding the Dutch army in its environmental management the context of Uruzgan province in Afghanistan. The module as such has to date not yet been put in fully integrated in the military learning environment. An introductory presentation to military representatives in the CivilMilitary Co-operation Centre of Excellence (CIMIC COE) however received positive feedback, in acknowledging the importance of addressing such concepts in their education material.

The future will tell whether the training module will motivate military to actively put the stepwise approach in practice during their missions. Previous similar exercises have led to positive results, where practitioners in the fields of tourism and water management valued the tool as necessary in their own activity planning.

Acknowledgements. Many thanks go to the commander of the NATO-accredited Civil-Military Co-operation Centre of Excellence, who made it possible to produce a training module and publication around the theme 'ecosystem approach' in the military environment. Throughout the process of producing the training module, the staff of the centre provided valuable material and financial inputs, but most importantly their comments were very useful to improve the applicability of the module in a military setting.

\section{References}

Chambers, R. 1994. The origins and practice of participatory rural appraisal. - World Development, 22(7), 953-969.

Sayre, R., Roca, E., Sedaghatkish, G., Young, B., Keel, S., Roca, R., Sheppard, S. 2000. Nature in Focus: Rapid Ecological Assessment. Island Press, Washington, DC, USA.

Shepherd, G. 2008. The ecosystem approach: five steps to implementation. Ecosystem Management Series no. 003, Gland, IUCN Commission on Ecosystem Management.

Appendix 1. The 12 principles of the Ecosystem Approach (Shepherd, 2008). Source: CBD.

Principle 1: The objectives of management of land, water and living resources are a matter of societal choice.

Principle 2: Management should be decentralized to the lowest appropriate level.

Principle 3: Ecosystem managers should consider the effects (actual or potential) of their activities on adjacent and other ecosystems.

Principle 4: Recognizing potential gains from management, there is usually a need to understand and manage the ecosystem in an economic context.

Principle 5: Conservation of ecosystem structure and functioning, in order to maintain ecosystem services, should be a priority target of the ecosystem approach.

Principle 6: Ecosystem must be managed within the limits of their functioning.

Principle 7: The ecosystem approach should be undertaken at the appropriate spatial and temporal scales.

Principle 8: Recognizing the varying temporal scales and lag-effects that characterize ecosystem processes, objectives for ecosystem management should be set for the long term.

Principle 9: Management must recognize the change is inevitable.

Principle 10: The ecosystem approach should seek the appropriate balance between, and integration of, conservation and use of biological diversity.

Principle 11: The ecosystem approach should consider all forms of relevant information, including scientific and indigenous and local knowledge, innovations and practices.

Principle 12: The ecosystem approach should involve all relevant sectors of society and scientific disciplines. 
Appendix 2. Overview of the steps of REAMil.
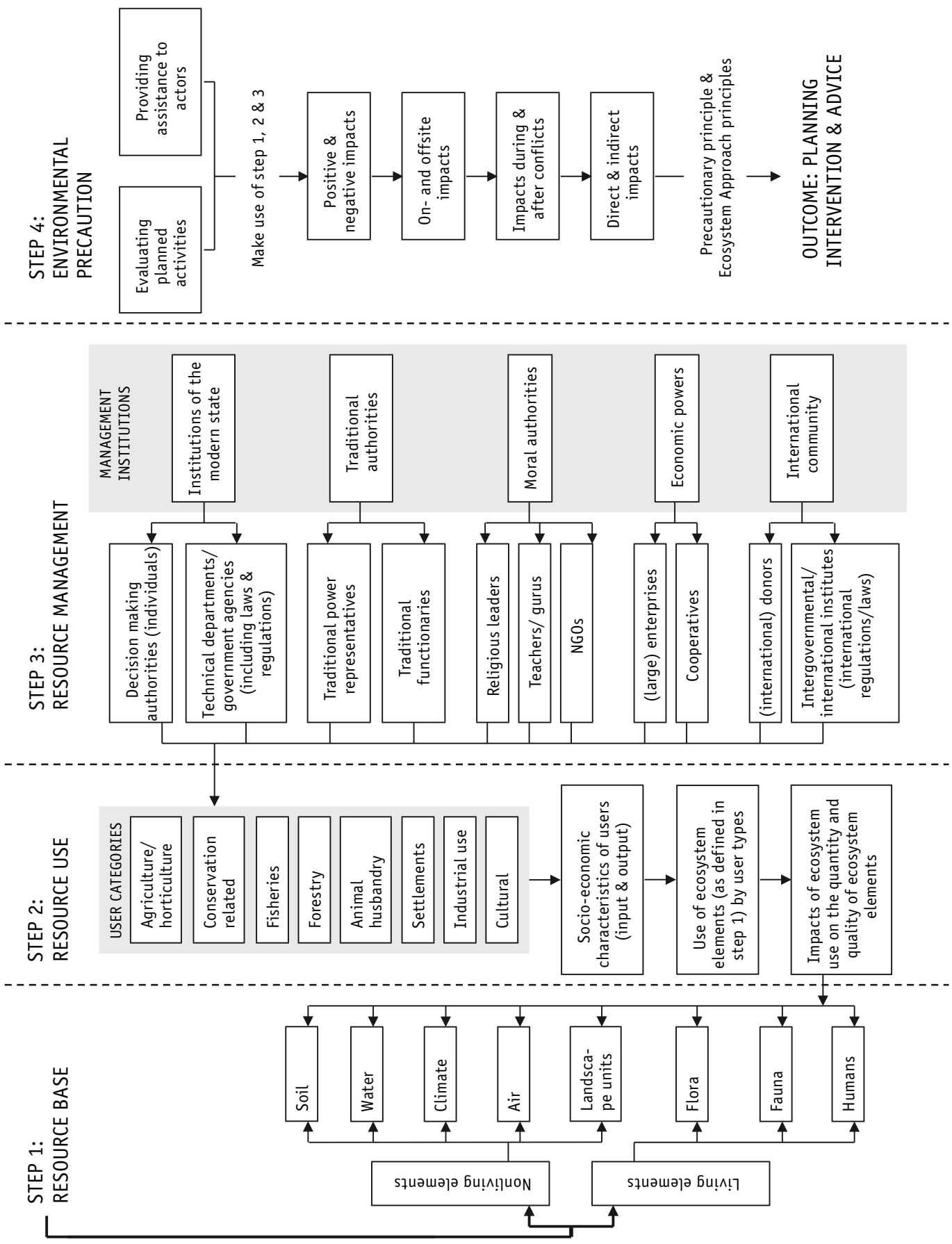